\title{
Fortalezas, debilidades y oportunidades de la política de gestión diferenciada de residuos para grandes generadores del área metropolitana de Buenos Aires (2013-2017). ¿Promoción del reciclaje inclusivo o más de lo mismo?
}

\section{Strengths, weaknesses and opportunities of the waste management policy oriented to the big generators of the metropolitan area of Buenos Aires (2013-2017). Promotion of inclusive recycling or more of the same?}

Faustina Sarandón IdIHCS-CONICET-UNLP, UNSAdA (Argentina) faustinasarandon@gmail.com

\section{NOTA BIOGRÁFICA}

Licenciada en Sociología y Doctoranda en Ciencias Sociales de la Universidad Nacional de La Plata, Becaria del Consejo Nacional de Investigaciones Científicas y Técnicas (CONICET). Investiga la incorporación de Recuperadores Urbanos a la gestión de residuos sólidos municipal.

Pablo Javier Schamber UNQ-CONICET, UNLa, UNAJ (Argentina) ORCID: http://orcid.org/0000-0002-3458-3182 pjschamber@hotmail.com

\section{NOTA BIOGRÁFICA}

Doctor en Antropología (UBA), Magister en Ciencia Política (Fund. Bco. Patricios) y Especialista en Gerencia Pública para el Desarrollo Social (INAP). Director del proyecto "Ambiente, sustentabilidad y residuos. La universidad fortaleciendo el reciclaje con inclusión social”, aprobado según requisitos Programa de Incentivos Ministerio de Educación de la Nación de Argentina (80020170500003LA).

\section{RESUMEN}

La política de gestión diferenciada de residuos para grandes generadores impulsada por la autoridad ambiental de la Provincia de Buenos Aires en el año 2013, auguraba un cambio sustancial en el tratamiento de los residuos sólidos urbanos. Con su entrada en vigencia, los grandes generadores debían gestionar sus propios residuos separándolos en al menos dos fracciones (reciclables y no reciclables) y asumir el costo de su transporte y tratamiento. Dichas normativas buscaban además promover la inclusión social de los recuperadores urbanos habilitando su participación mediante la organización de cooperativas. Desde un enfoque de las políticas públicas como proceso, este trabajo expone análisis iniciales sobre los efectos que dicha política ha venido teniendo sobre actores que la protagonizan. 
GAPP. Nueva Época - N. 21, Mayo-Octubre 2019 - ISSN: 1989-8991 - DOI: 10.24965/gapp.v0i21.10559 - [Págs. 61-79]

Fortalezas, debilidades y oportunidades de la política de gestión diferenciada de residuos para grandes generadores del área..

Faustina Sarandón / Pablo Javier Schamber

\title{
PALABRAS CLAVE
}

Políticas públicas; residuos sólidos urbanos; Cooperativas de Recuperadores Urbanos; desarrollo sustentable; implementación.

\begin{abstract}
The policy of differentiated management of waste for large generators promoted by the environmental authority of Buenos Aires Province in 2013, predicted a substantial change in the treatment of urban solid waste. Through them, big generators had to manage their own waste by separating them into at least two fractions (recyclable and non-recyclable) and to assume the cost of transporting and treating them. These regulations also sought to promote the social inclusion of waste pickers enabling their participation through the organization of cooperatives. From an approach of the public policies as process, this work exposes initial analyzes on the effects that this policy has been having on actors that carry it out.
\end{abstract}

\section{KEYWORDS}

Public policies; Urban Solid Waste; Waste pickers cooperatives; sustainable development; implementation.

\section{SUMARIO}

INTRODUCCIÓN. OBJETO DE ESTUDIO. ENFOQUE/MARCO TEÓRICO. METODOLOGÍA. PLAN DE EXPOSICIÓN. 1. LOS GRANDES GENERADORES. 1.1. PLANES DE GESTIÓN. 1.2. TIPOS DE GRANDES GENERADORES QUE PRESENTARON PLANES DE GESTIÓN. 1.3. REFERENTES AMBIENTALES. 2. LOS DESTINOS SUSTENTABLES. 2.1. DILEMAS DE COBRAR POR EL SERVICIO DE RECIBIR. 2.2. INSCRIPCIÓN AL REGISTRO DE TECNOLOGÍAS. 2.3. TRANSPORTE. 2.4. MUNICIPIOS. 2.5. CERTIFICADOS. 3. SOBRE LA RELACIÓN ENTRE GRANDES GENERADORES Y DESTINOS SUSTENTABLES SEGÚN LOS PLANES DE GESTIÓN. 3.1. ALGUNOS CASOS. 3.1.1. Asociación Vecinal Nordelta y Coop. Creando Conciencia (Res. 137). 3.1.2. Clorox SA., Reciclando Sueños, Consejo Nacional de Investigaciones Científico Tecnológicas (CONICET) (Res. 139/13). 3.1.3. Grupo Newsan y Cooperativa Bella Flor. 3.1.4. Carrefour, Mc Donald's (Res. núm. 138/13) y varios destinos sustentables. 3.1.5. Universidades Nacionales del Conurbano y cooperativas. 4. REFLEXIONES FINALES. REFERENCIAS BIBLIOGRÁFICAS. NORMATIVA DE REFERENCIA.

\section{INTRODUCCIÓN}

\section{Objeto de estudio}

En Argentina, de acuerdo a la Constitución Nacional, las provincias delegan en la Nación la potestad de dictar normas de presupuestos mínimos de protección ambiental. Para el caso de los residuos sólidos urbanos (RSU) ${ }^{1}$ es la Ley 25916/04 la que define dichos estándares que todas las jurisdicciones deben cumplir como mínimo, pudiendo también dictar medidas más exigentes. En este sentido, desde hace algunos años varias provincias sancionaron normativas complementarias y ampliatorias de aquellos presupuestos mínimos. Así, han establecido distinciones entre dos tipos de generadores: los generadores individuales y los grandes generadores; los primeros permanecen dentro del servicio público de recolección local, mientras que los grandes generadores deben afrontar ahora el transporte y tratamiento.

En la provincia de Buenos Aires, la Ley núm. 14273 del año 2011 estableció que los grandes generadores debían hacerse cargo de los costos del transporte y la disposición final de los mismos en los rellenos sanitarios de la Coordinación Ecológica Área Metropolitana Sociedad del Estado (CEAMSE) ${ }^{2}$. Sin embargo, es

\footnotetext{
1 Los residuos sólidos urbanos (RSU) en general comprenden plásticos, papeles, diarios y revistas, vidrios, latas, muebles y electrodomésticos viejos, embalajes y desperdicios de la actividad comercial, restos de comida, cáscara de frutas y verduras, restos del cuidado de los jardines, la limpieza de las calles, entre otros. Quedan excluidos de esta categorización los residuos patogénicos regidos por la Ley núm. 154, los residuos peligrosos regidos por la Ley Nacional núm. 24051 y por la Ley núm. 2214, y los residuos industriales regidos por la Ley Nacional núm. 25612, que a su vez tienen debido a sus características otros sistemas de manejo.

2 CEAMSE es una empresa pública interjurisdiccional (Provincia de Buenos Aires y Ciudad Autónoma de Buenos Aires) encargada de administrar en rellenos sanitarios la disposición de los residuos sólidos urbanos de 34 distritos que componen el área metropolitana de Buenos Aires, donde habitan más de 15 millones de personas.
} 
difícil encontrar en esa medida otra justificación que no sea dotar de nuevos recursos financieros a CEAMSE e incrementar la cartera de clientes de las empresas autorizadas para transportar residuos. En cambio, las Resoluciones núm. 137, 138 y 139 del año 2013 impulsadas por la autoridad ambiental de la misma provincia (el Organismo Provincial para el Desarrollo Sostenible/OPDS) ${ }^{3}$, si bien tienen un parecido de familia con la mencionada Ley, presentan respecto de aquella una diferencia radical al establecer la obligatoriedad de separar los residuos en al menos dos categorías (reciclables y no reciclables), y al crear la figura del destino sustentable para el tratamiento de la fracción reciclable. Pero además de promover maximizar la recuperación de los materiales reciclables producidos por grandes generadores y, consecuentemente, disminuir el volumen destinado a disposición final, dichas normativas estimulan la inclusión social al reconocer explícitamente que los recuperadores urbanos organizados en cooperativas pueden participar como destinos sustentables. Las Resoluciones no establecen distinciones en relación a los tipos de figuras jurídicas susceptibles de inscribirse tales, pero tanto en sus considerandos como en sus articulados se encuentran claras referencias al propósito de beneficiar a las cooperativas de recuperadores urbanos. Transcurridos cuatro años de la existencia de las Resoluciones, este trabajo busca analizar aspectos relevantes de su puesta en marcha.

\section{Enfoque/marco teórico}

Recuperadores urbanos o recicladores es la denominación empleada en documentos públicos de Argentina para referir a los recolectores de residuos reciclables, también conocidos habitualmente como cartoneros y tiempo atrás como cirujas. La producción bibliográfica sobre diferentes aspectos de la práctica que ellos realizan ha sido profusa en los últimos años, sobre todo debido a interés que despertó el importante incremento de su número a partir del cambio de siglo. No es este el lugar para realizar un compendio de todas esas producciones, pero para tener al menos una aproximación a su nutrido volumen y sin pretensión de exhaustividad caben destacar entre las tesis de postgrado locales recientes a las siguientes (por orden alfabético): Álvarez 2011, Busso 2004, Dimarco 2010, Gorban 2005 y 2014, Maldovan Bonelli 2014, Molina 2017, Paiva 2008, Perelman 2011, Schamber 2008, Shammah 2009, Sorroche 2016, Suárez 2001 y 2016, Villanova 2014, entre otras realizadas en el marco de lo que Álvarez (2011) identificó como antropológicas para distinguir a las que se inscriben dentro del campo de las ciencias sociales de las más vinculadas con el ámbito de la ingeniería sanitaria ${ }^{4}$. También debe tenerse en cuenta que en la construcción de la agenda sobre esta problemática (Oszlak \& O'Donnell, 1981; Subirats, 1994) las organizaciones reconocidas como cooperativas de recuperadores urbanos se fueron identificando en Argentina como beneficiarios de los modelos de gestión de residuos con inclusión social. Con fuerte intervención de ONGs de carácter internacional (como AVINA, COSPE, GREENPEACE, entre otras), se posibilitó que las cooperativas se volvieran tanto receptoras de las políticas de gestión de los residuos como parte activa en la elaboración de las mismas (Sorroche, 2016).

Los enfoques que analizan las políticas públicas como un proceso constituido por distintas etapas, con actores, restricciones, decisiones, desarrollos y resultados que se influyen, interrelacionan y retroalimentan (Aguilar Villanueva, 1993 y 1996; Regonini, 1991, Tamayo Sáez, 1997) resultan útiles para contemplar el devenir de las Resoluciones del OPDS. Sin considerar que en la realidad las cosas hayan sucedido tal como se las analiza o representa, constituyen un dispositivo metodológico que permite la descripción y comprensión de una política separándola en etapas sucesivas (Aguilar Villanueva, 1996; Oszlak \& O’Donnell, 1981; Tamayo Sáez, 1997). Muy pocos trabajos han analizado las etapas de definición y construcción de la agenda, de toma de decisión e implementación de las primeras acciones en relación a estas mismas Resoluciones de las que aquí nos ocupamos (Sarandón, 2016, 2016 b). Considerando el tiempo transcurrido desde su existencia, ahora nos centraremos en analizar algunos efectos derivados de esas medidas sobre los actores identificados como los protagonistas de su implementación: grandes generadores, destinos sustentables y OPDS. No procuramos lograr una evaluación de las Resoluciones ni de los cambios que se observan en relación a una determinada situación inicial, ya que para ello se debería contar con una línea de base,

${ }^{3}$ EI OPDS es la autoridad ambiental de la Provincia de Buenos Aires y tiene como funciones planificar, formular, proyectar, fiscalizar, ejecutar la política ambiental y preservar los recursos naturales; ejercer el poder de policía, establecer y fiscalizar el cumplimiento de la política sobre contaminación industrial, sus efluentes y del ambiente en general; intervenir en la conservación, protección y recuperación de reservas, áreas protegidas y bosques, en el uso racional y la recuperación de suelos; la promoción de actividades vinculadas con la educación ambiental y con los estudios de impacto ambiental, entre otras (Decreto del Poder Ejecutivo Provincial 23 de 2007).

${ }_{4}$ Un panorama adicional sobre la situación en Argentina y otros países de América Latina puede encontrarse en las compilaciones de artículos reunidos en los diferentes cinco volúmenes de los libros "Recicloscopios" (ver bibliografía). 
además de haber sido planificada esa acción desde los inicios de la política y como parte de la misma. Más bien pretendemos analizar cómo se ha venido dando la implementación de las Resoluciones teniendo en cuenta las aspiraciones y el espíritu contenido en papel, las acciones encaradas por sus protagonistas y algunos resultados alcanzados hasta fines del año 2017. En este sentido, interesa precisar ¿predominan las cooperativas de recuperadores urbanos entre los destinos sustentables con los que se vinculan los grandes generadores?, ¿cómo se ha dado la interacción entre los destinos sustentables, los grandes generadores y el OPDS?, ¿qué dificultades se presentaron y cómo se resolvieron?, ¿qué modificaciones se pueden identificar a partir del cambio de gestión provincial en diciembre de $2015^{5}$ ?, entre otras aristas de indagación.

\section{Metodología}

Para realizar este análisis utilizamos una metodología basada en entrevistas en profundidad a funcionarios y técnicos del OPDS, y a referentes y miembros de cooperativas de recuperadores urbanos. También utilizamos información provista por el OPDS en una base de datos Excel actualizada hasta diciembre de 2017, donde se volcaron datos extraídos de los planes de gestión que tuvieron que presentar los grandes generadores. Asimismo, un valioso material han sido los registros de campo e informes producidos en el marco de jornadas de trabajo realizadas entre varias cooperativas, y entre cooperativas y grandes generadores llevadas a cabo en el marco de proyectos de investigación y transferencia en los que participamos (Proyecto UNAJ SPU 4663/14 núm. 001-107; Proyecto PDTS CIN CONICET núm. 594, UNLa núm. 33A246, UNLa 80020170500003LA)6.

\section{Plan de exposición}

Este trabajo se encuentra dividido en tres secciones. Las dos primeras están dedicadas a describir varios aspectos que hacen al estado de situación en que se encuentran los dos principales actores involucrados en las Resoluciones (grandes generadores y destinos sustentables). Luego se analizan la relación que entre ellos se ha venido estableciendo a partir de los datos que surgen de los planes de gestión presentados al OPDS. Esta misma parte contiene referencia a algunos casos en los que grandes generadores entregan sus residuos reciclables a cooperativas de recuperadores urbanos para su tratamiento. Por último aparecen reflexiones sobre cómo se han venido instrumentando las Resoluciones y se explicitan propuestas que estimamos apuntan a su mejora.

\section{LOS GRANDES GENERADORES}

En esta sección analizaremos a los grandes generadores como uno de los actores principales de las Resoluciones. Los grandes generadores implicados en la normativa son los Clubes de Campo y Barrios Cerrados (Res. 137/13), los hoteles de cuatro y cinco estrellas, los shoppings y galerías comerciales, los hipermercados y las cadenas de locales de comidas rápidas (Res. 138/13), y los establecimientos industriales (Res. 139/13). La política exige a los grandes generadores adoptar sistemas de separación interna de residuos en al menos dos fracciones (reciclables y no reciclables) y responsabilizarse por los costos del transporte y tratamiento de ambas. Aunque muchos grandes generadores venían implementando donaciones de material reciclable a cooperativas de recuperadores urbanos o asociaciones civiles con anterioridad a la existencia de las Resoluciones, es cuando éstas comienzan a instrumentarse que aparece la obligación de hacerlo a un destino sustentable y asumiendo el costo del transporte y del tratamiento de los materiales reciclables, y de presentar todo ello en el marco de un Plan de Gestión. Consultado sobre cómo repercutieron en algunos de ellos esta medida, el entonces Director de Residuos Sólidos Urbanos del OPDS respondió:

\footnotetext{
5 Entre octubre y noviembre de 2015 se realizaron elecciones generales en el país y en varias provincias y Municipios. En la provincia de Buenos Aires resultó electa gobernador la candidata de un partido opositor al que ejercía el poder entonces. En diciembre de ese año asumieron las nuevas autoridades.

6 Se realizaron cuatro jornadas de trabajo: "1. Encuentro Cooperativas de Recuperadores Urbanos y Universidades: Taller de evaluación de la implementación de las Resoluciones de GG del OPDS" (3-08-2015), "2. Encuentro Cooperativas de Recuperadores Urbanos y Universidades: Taller sobre manifiesto electrónico y certificados de tratamiento de RSU reciclables" (27-10-2015), "I Jornada para el Debate Programático Cooperativas de Cartoneros/Recuperadores y Universidades Nacionales" (4-07-2016) y "II Jornada para el Debate Programático Cooperativas de Cartoneros/Recuperadores y Universidades" (16-11-2016).
} 
....al principio lo tomaron mal, pero después se fueron aflojando, y en general está bien recibido. Lo que se logró es tomar conciencia de que había que separar los residuos, de que había que valorizarlos. El tema, digamos, ambiental también está en auge y hay muchos que están en eso... (entrevista al Director de RSU, 10-08-15).

\subsection{Planes de Gestión}

Los grandes generadores deben presentar ante el OPDS un Plan de Gestión en el que se identifique un Referente Ambiental (responsable del diseño y la ejecución del Plan y nexo con el OPDS), un transportista y un destino sustentable escogido para el tratamiento (Anexo único, Res. núm. 137/13). Además, se tiene que estimar qué cantidad de RSU se produce por mes (indicador de generación) y cuánto de ello es potencialmente recuperable (indicador de materiales recuperados). Estos datos permiten calcular la tasa de reciclado, que expresa la relación entre RSU generados y RSU reciclables. Por último, el gran generador debe contar con un Libro de operaciones para el registro de las cantidades de RSU reciclables llevadas al destino sustentable y las cantidades de RSU no reciclables transportadas al sitio de disposición final de CEAMSE. Esto debe estar acompañado por los certificados que tanto el destino sustentable como la CEAMSE proveen para cada caso. Este Libro de operaciones sirve al OPDS para tareas de fiscalización del cumplimiento de las Resoluciones.

El Plan de Gestión es evaluado por el OPDS y debe ser actualizado por el referente ambiental anualmente. Hasta diciembre de 2017 se habían presentado ante OPDS 432 Planes de Gestión. En el siguiente Gráfico 1 pueden distinguirse según el tipo de Resolución en el que se enmarcan (ver más adelante) y el año en que se presentaron ${ }^{7}$.

\section{GRÁFICO 1 PLANES DE GESTIÓN SEGÚN EL TIPO DE RESOLUCIÓN Y EL AÑo DE PRESENTACIÓN}

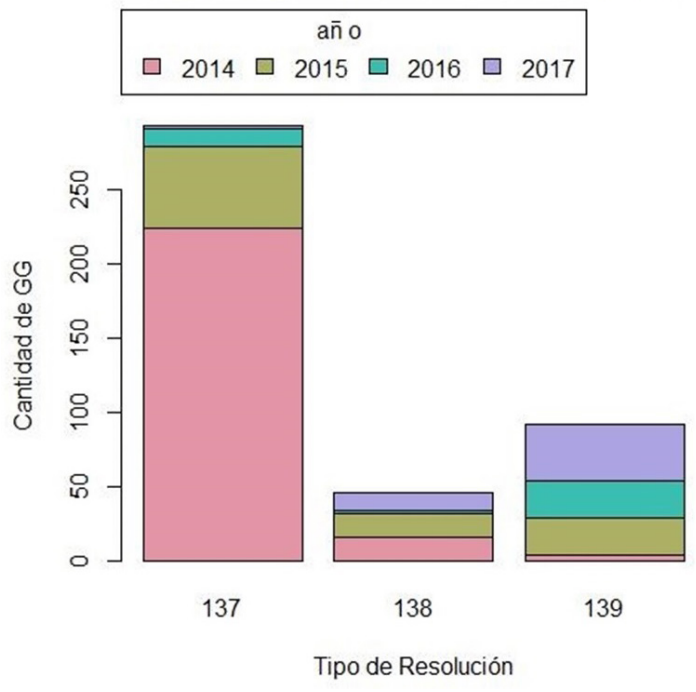

Fuente: elaboración propia sobre base de datos de OPDS.

\subsection{Tipos de grandes generadores que presentaron Planes de Gestión}

La distribución porcentual del tipo de gran generador de acuerdo a su respectiva resolución es la siguiente: el 68\% pertenece a la Resolución 137 (Countries y Barrios Cerrados), casi un 11\% a la Resolución 138 (Galerías comerciales, Hipermercados, cadenas de comida rápida y Hoteles de 4 y 5 estrellas), y un $21 \%$ a la Resolución 139 (Industrias). Se observa que el 57\% de los Planes de Gestión se presentó durante el primer año en que se instrumentaron las Resoluciones, pero además se puede identificar que de ese valor, el $92 \%$ fueron Planes de Gestión presentados por Countries y Barrios cerrados. Junto al recambio de autoridades en la Provincia y en

7 Se aclara que esta variable indica el año de presentación de los Planes de Gestión, y no se relaciona con las actualizaciones que deben realizarse anualmente por parte de los grandes generadores ni con la fecha de su eventual aprobación. 
GAPP. Nueva Época - N. 21, Mayo-Octubre 2019 - ISSN: 1989-8991 - DOI: 10.24965/gapp.v0i21.10559 - [Págs. 61-79]

Fortalezas, debilidades y oportunidades de la política de gestión diferenciada de residuos para grandes generadores del área..

Faustina Sarandón / Pablo Javier Schamber

varios de los municipios involucrados, en el año 2016 descienden notablemente las presentaciones de Planes de Gestión. No obstante, en el año 2017 se nota un incremento de la presentación de Planes de Gestión respecto de la caída del año anterior, pero ahora resultan preponderantes los pertenecientes a la Resolución 139 (Industrias).

\subsection{Referentes ambientales}

Para los 432 Planes de Gestión presentados existen 152 personas identificadas como referentes ambientales. Hay consultoras privadas que ofrecen a los grandes generadores una respuesta integral frente a las obligaciones impuestas por las Resoluciones: referente ambiental, planificación, diseño e implementación del Plan de Gestión a la medida de las necesidades del generador, contacto con el OPDS, contratación del transporte y del destino sustentable. También se observan empresas que antes de las Resoluciones sólo realizaban el transporte de residuos, y que ahora sumaron a sus actividades la oferta del referente ambiental y los mismos servicios que ofrecen las consultoras privadas. Si bien la mayoría de los referentes ambientales representan a un único gran generador, existen algunos pocos casos que concentran la representación de un número importante de ellos. El referente ambiental que lidera este conjunto tiene 73 grandes generadores (69 en la Resolución 137 y cuatro en la 138), es decir que se trata del referente ambiental de casi el $17 \%$ de los Planes de Gestión presentados. Le sigue quien es referente ambiental de 29 grandes generadores, todos ellos vinculados a la Resolución 137. Luego hay otro con 22, otro con 19 y más atrás uno con 13 . Si se consideran a los cinco referentes ambientales que cumplen ese rol en la mayor cantidad de grandes generadores, ellos concentran poco más del $35 \%$ de los Planes de Gestión presentados.

\section{LOS DESTINOS SUSTENTABLES}

Los recuperadores urbanos agrupados en cooperativas se fueron identificando en Argentina como los encargados de gestionar los residuos reciclables, insertándose como un actor que abarca la generación de empleo, la organización barrial y las problemáticas ambientales (Angélico y Maldovan, 2008) ${ }^{8}$. Las Resoluciones de OPDS constituyen un ejemplo de ello al reconocer explícitamente que los recuperadores urbanos organizados en cooperativas pueden participar como Destinos Sustentables que brindan servicios a los grandes generadores. Para poder tener dicho reconocimiento los interesados deben inscribirse en el Registro de Tecnologías del OPDS (regido por la Resolución núm. 367/10). Con el fin de facilitar la inscripción de las cooperativas de cartoneros a dicho Registro, el OPDS introdujo la Resolución núm. 20/14 que elimina y simplifica los trámites para obtener la habilitación. En efecto, en los considerandos de esta última Resolución se menciona

Que corresponde efectuar un distingo para las actividades de escasa complejidad como el acopio o almacenamiento transitorio, segregación, acondicionamiento, enfardado, prensado y compactado de los residuos sólidos urbanos, adecuando en esta instancia los requisitos que deben cumplimentarse al inscribir este tipo de tecnologías»... y «Que para dar cumplimiento a lo resuelto y lograr una gestión exitosa las cooperativas de clasificación y recuperación de residuos sólidos urbanos resultan un actor fundamental» (Res. 20/14, nuestro subrayado).

Si bien las modificaciones incluidas con la Resolución 20/14 no establecen distinciones en relación a los tipos de figuras jurídicas que pueden inscribirse, sino en torno a actividades de escasa complejidad, tanto esta modificación como las propias Resoluciones que afectan a los grandes generadores fueron hechas con el claro propósito de beneficiar a las cooperativas de cartoneros. Ello puede advertirse por ejemplo en la letra de las Resoluciones cuando dicen tener el objetivo de:

«implementar las acciones para maximizar el recupero de los materiales reciclables y/o valorizables, y disminuir el volumen destinado a disposición final, de acuerdo a las definiciones que aquí se establecen, promoviendo la inclusión social y el desarrollo económico de las cooperativas, pues mejoran la productividad marginal e incrementan la masa de trabajadores» (Res. 137/13).

Sin embargo, dicho propósito no logra plasmarse en los hechos, como se irá viendo a lo largo de este trabajo. En lo que sigue se repasan y analizan algunos dificultades que han tenido las cooperativas ya sea para lograr su habilitación como destino sustentable, o bien para gozar de los beneficios que estipulaban las Resoluciones.

${ }^{8}$ Para un seguimiento cronológico de este proceso puede consultarse (en este orden): SCHAMBER y BORDAGARAY (2017), PAIVA (2008) y SORROCHE (2017). 


\subsection{Dilemas de cobrar por el servicio de recibir}

Las Resoluciones fueron muy bienvenidas por los referentes de las cooperativas de recuperadores urbanos ya que las consideraron como un reconocimiento de su rol por parte del OPDS, y como una oportunidad para aumentar sus ingresos. Ya no se trataba sólo de recibir la filantrópica ofrenda de los residuos reciclables de un gran generador, que de ese modo disminuye lo que debería abonar a CEAMSE al disponerlos de acuerdo a la citada Ley 14273 del año 2011, sino que ahora con las Resoluciones tenían la posibilidad de habilitar sus galpones como destinos sustentables y cobrar por todo o parte del servicio brindado (recepción y tratamiento sin dudas, y en ciertos casos también retiro y transporte). En palabras del presidente de una cooperativa de la zona sur del gran Buenos Aires:

Si vos hacés un acuerdo con un gran generador de las dimensiones de Mc Donalds o Carrefour... va a haber trabajo y se va a generar ingreso de dinero. ¿Cómo no vas a pagar un proceso de reciclado? Si vos como sociedad pagás un proceso de entierro de basura, ¿cómo no vas a pagar un proceso de reciclado? Las empresas y hasta los mismos municipios te quieren pagar dándote basura, no quiere pagar por el servicio de reciclado (Entrevista a Eduardo, 15 de enero de 2016).

Muchas cooperativas que habilitaron su galpón como destino sustentable acordaron establecer un precio mínimo común por cada servicio brindado (recolección, transporte, recepción y tratamiento). El 27 de febrero de 2014 se realizó un encuentro entre cooperativas, con acompañamiento del Instituto Nacional de Tecnología Industrial (INTI), la Universidad Nacional de La Plata y el OPDS donde se acordaron criterios de cálculo para el establecimiento de dicha tarifa. El valor de la tonelada de RSU enterrada en CEAMSE fue utilizado como referencia (Sarandón, 2016:101). No obstante, los acuerdos no fueron cumplidos y muchas cooperativas continuaron recibiendo material sin cobrar. Las argumentaciones surgidas durante las entrevistas con referentes de las mismas dan cuenta de la heterogeneidad de intereses y estrategias existentes entre ellas, y las diferencias existentes en relación a la calidad y cantidad de residuos reciclables provistos por grandes generadores con quienes cada una ha ido construyendo relaciones. Plantear que la recepción gratuita de material comercializable pasara de pronto a constituirse en un servicio que se cobra, implicó para algunas cooperativas el claro riesgo de perder proveedores. Estas disyuntivas se evidenciaron en los reportes de las mesas de trabajo organizadas en el marco de los talleres realizados por las Universidades con las cooperativas del Área Metropolitana de la provincia de Buenos Aires, tal como puede apreciarse en la Tabla 1:

TABLA 1. REPORTE DE MESAS DE TRABAJO EN EL $1 .^{\circ}$ ENCUENTRO ENTRE COOPERATIVAS DE RECUPERADORES URBANOS Y UNIVERSIDADES

Taller de evaluación de la implementación de las Resoluciones de OPDS. UNAJ 3-08-2015 - INFORME TÉCNICO núm. 1

\begin{tabular}{|c|c|}
\hline $\begin{array}{l}\text { Mesa 1: información y acceso } \\
\text { como destino sustentable }\end{array}$ & $\begin{array}{l}\text { Mesa 2: Contacto y diálogo } \\
\text { con grandes generadores }\end{array}$ \\
\hline $\begin{array}{l}\text { «A pesar de que en el marco de una capacitación promovida desde } \\
\text { el OPDS e implementada por INTI se habían establecido criterios } \\
\text { para el cobro a los grandes generadores por la prestación del ser- } \\
\text { vicio de retiro, no todas las cooperativas respetan dichos criterios, } \\
\text { e incluso varias lo realizan de modo gratuito. Esto representa un } \\
\text { inconveniente para quienes sí cobran. En este sentido, algunos de } \\
\text { los participantes se mostraron a favor de que la OPDS establezca } \\
\text { en las Resoluciones las tarifas mínimas que deben cobrarse»... } \\
\text { «En varios casos (cooperativa de Villa Itatí) tener la habilitación } \\
\text { como Destino Sustentable no representó ningún cambio respecto } \\
\text { de situaciones preexistentes. No se sienten ahora en condiciones } \\
\text { de exigir el cobro a empresas a las que hasta ahora les retiran en } \\
\text { forma gratuita. Tampoco implicó aumentar el número de grandes } \\
\text { generadores. En algunos casos, tener la habilitación como Desti- } \\
\text { no Sustentable resultó contraproducente, ya que algunos grandes } \\
\text { generadores dejaron de entregarles el material por ese motivo». }\end{array}$ & $\begin{array}{l}\text { «No todas las Cooperativas cobran por el Ser- } \\
\text { vicio y esto genera un problema interno entre } \\
\text { las Cooperativas. Algunas voces decían que se } \\
\text { les hacía muy difícil lograr que el gran genera- } \\
\text { dor pague por el servicio, entonces aceptaban } \\
\text { igual el trabajo porque les sirve el material. Si- } \\
\text { gue muy presente la idea de que lo pactado en } \\
\text { el Taller de costos es lo que se debe respetar». }\end{array}$ \\
\hline
\end{tabular}

Fuente: elaboración propia en base a los diálogos del taller. 
Se observó durante ese taller la demanda de las cooperativas más consolidadas para que OPDS intervenga regulando el cobro de los servicios. Los funcionarios y técnicos del OPDS sostuvieron la posición de no mediar sobre los acuerdos que se establecen entre grandes generadores y destinos sustentables. Al ser entrevistado para este trabajo, el encargado del Área de Cooperativas del OPDS manifestó que dicho organismo no puede involucrarse en dichas cuestiones. Si bien reconoció que desde el organismo recomiendan a los grandes generadores elegir a cooperativas como destinos sustentables, sospecha que si además les impusieran la obligatoriedad del pago por los servicios prestados, los grandes generadores preferirían contratar empresas privadas.

\subsection{Inscripción al Registro de Tecnologías}

Más allá de las facilidades que para la inscripción de las cooperativas en el Registro de Tecnologías significó la Resolución núm. 20/14 de OPDS, la realización del trámite de todos modos requiere la presentación de cierta documentación (estatuto, clave única de identificación tributaria -cuit-, domicilio, etc.) acompañada de un informe técnico realizado por un profesional inscripto en el Registro de Profesionales del OPDS (Resolución núm. 195/96). Dicho informe debe dar cuenta de cómo trabaja la cooperativa, cómo son sus instalaciones, qué tipo y qué cantidades de materiales procesan, entre otra información que se le solicita. Este informe es evaluado por el personal del Registro de Tecnologías y una vez aprobado la cooperativa recibe una Disposición firmada por el Director provincial del Residuos del OPDS con la habilitación. Desde el año 2016, con la nueva gestión al frente del OPDS, además de este procedimiento, los técnicos del organismo realizan una visita a la cooperativa para conocer las instalaciones y complementar la evaluación con observaciones in situ (Schamber y Sarandón, 2018). Como indicador de la falta de agilidad de OPDS para poder completar la evaluación de las solicitudes, sirva mencionar que el 9 de mayo del 2017, cooperativas nucleadas en la Federación Argentina de Cartoneros y Recicladores (FACyR) realizaron una marcha hacia la sede del OPDS en la ciudad de La Plata en reclamo de la falta de aprobación de varios expedientes presentados meses atrás (https://www.lanoticia1. com/noticia/marcha-cartonera-por-la-inclusion-en-la-provincia-de-buenos-aires-92121.html, vista 11-06-2018). En entrevistas con técnicos del organismo se corroboró que hacia fines de ese mismo año todavía existían 20 expedientes en trámite (presentaciones que fueron evaluadas pero que no fueron aprobadas por falta de información, de alguna firma o por no haber sido aún visitados por los técnicos del OPDS).

\subsection{Transporte}

En el caso específico de la Resolución núm. 139/13 que involucra a los grandes generadores que son industrias ${ }^{9}$, se establece que el vehículo que transporte los residuos debe estar registrado y habilitado de acuerdo a las normas que regulan el transporte de residuos especiales y/o patológicos ${ }^{10}$. Es decir, aunque las industrias generen residuos que no sean especiales y/o patológicos (a los que se suele denominar como «no especiales» o «asimilables a residuos sólidos urbanos»), su transporte debe cumplir los requisitos exigidos como si los fueran. Es decir, aún para el traslado de la fracción reciclable el transporte en estos casos debe cumplir con mayores requisitos que en el caso de los vehículos que trasladan residuos reciclables de los grandes generadores involucrados en las Resoluciones 137 y 138. Es oportuno aclarar que el registro y la habilitación del transporte de los residuos especiales también se realiza en el OPDS, pero es responsabilidad de una dirección distinta a la que tiene injerencia con los RSU (y por lo tanto con las Resoluciones). De este modo, a las empresas transportistas de residuos especiales la Resolución 139 les abrió de manera exclusiva un nuevo mercado, ante cuya oportunidad, adoptaron distintas estrategias. Algunas se inscribieron además como destino sustentable para poder realizar ya no sólo la recolección de reciclables sino también su tratamiento. Incluso varios grandes transportistas generaron instancias de difusión de las Resoluciones junto a autoridades de OPDS en instalaciones de grandes generadores que pasaron a ser sus clientes ${ }^{11}$.

\footnotetext{
9 Si bien se desconoce el motivo, actualmente esta Resolución se encuentra en estado de revisión (de hecho no figura en el sitio web de OPDS http://www.opds.gba.gov.ar/contenido/grandes_generadores donde sí aparecen las otras dos).

10 Los Residuos Especiales se encuentran definidos en la Ley núm. 11720/95 de la provincia de Buenos Aires. Los residuos especiales y patogénicos requieren un mayor seguimiento de su traslado por los riesgos ambientales que éstos implican, por lo tanto no pueden ser transportados por cualquier vehículo, sino que debe cumplir ciertas normas y cuidados. Resolución núm. $63 / 96$ Transporte de Residuos Especiales y/o Industriales. Ley Nacional núm. 25612/02.

11 Como ejemplo, en la página de internet de la empresa Ecoterra (http://www.ecoterrarecicla.com.ar/eventos), se exponen fotos algunos de ellos.
} 
GAPP. Nueva Época - N. 21, Mayo-Octubre 2019 - ISSN: 1989-8991 - DOI: 10.24965/gapp.v0i21.10559 - [Págs. 61-79]

Fortalezas, debilidades y oportunidades de la política de gestión diferenciada de residuos para grandes generadores del área..

Faustina Sarandón / Pablo Javier Schamber

Las cooperativas de recuperadores urbanos interesadas en transportar y tratar los residuos reciclables de las industrias también explicitaron esta problemática en oportunidad del taller antes citado:

TABLA 2. REPORTE DE MESAS DE TRABAJO EN EL $10^{\circ}$ ENCUENTRO ENTRE COOPERATIVAS

DE RECUPERADORES URBANOS Y UNIVERSIDADES

Taller de evaluación de la implementación de las Resoluciones del OPDS.

UNAJ 3-08-2015 - INFORME TÉCNICO núm. 1

\begin{tabular}{l} 
Mesa 3: Transporte e Infraestructura \\
\hline «La imposibilidad de adquirir nuevos transportes o mejorar las condiciones de los ya existentes fue un punto en \\
común en la mayoría de las cooperativas. La dificultad para realizar un mantenimiento adecuado, el combustible \\
y los problemas de papeles son los impedimentos más frecuentes. Por este motivo muchas de las cooperativas \\
deben alquilar el transporte a terceros porque no pueden tener sus vehículos propios. Esta situación implica el \\
aumento de sus costos ya que deben abonar a transportistas por el retiro de los materiales. En algunas ocasiones \\
logran conseguir camiones pero son compactadores y no les sirven para llevar a cabo su trabajo porque terminan \\
comprimiendo y contaminando los materiales reciclables. Por lo tanto, el vehículo más apropiado es el camión \\
con caja seca».
\end{tabular}

Fuente: elaboración propia en base a los diálogos del taller.

En la base de datos del OPDS construida con información suministrada por los planes de gestión presentados por los grandes generadores, se pueden identificar 66 transportistas de residuos reciclables, de los cuales más del $75 \%$ son empresas privadas mientras que el resto son asociaciones y cooperativas. Si se analiza por tipo de Resolución se observa que las cooperativas y asociaciones tienen mayor presencia como transportistas de los residuos reciclables en los countries y barrios cerrados, lo que corrobora la dificultad mencionada para poder brindar el servicio de transporte a las industrias.

TABLA 3 TIPOS DE TRANSPORTE DE RECICLABLES SEGÚN TIPO DE GENERADOR

\begin{tabular}{lcccccc}
\hline \multirow{2}{*}{$\begin{array}{c}\text { Tipo de } \\
\text { transportista }\end{array}$} & \multicolumn{2}{c}{ Núm. de Resoluciones } & \multirow{2}{*}{ Total } & $\%$ \\
\cline { 2 - 5 } & 137 & $\mathbf{1 3 8}$ & $\mathbf{1 3 9}$ & & \\
\hline Empresa & 225 & 24 & 46 & 295 & $85,5 \%$ \\
\hline Varias empresas & 0 & 2 & 8 & 10 & $2,9 \%$ \\
\hline Coop. y Asociaciones & 14 & 6 & $10^{12}$ & 30 & $8,7 \%$ \\
\hline Municipal & 8 & 1 & 1 & 10 & $2,9 \%$ \\
\hline Total & 247 & 33 & 65 & 345 & $100,0 \%$ \\
\hline$\%$ & $71,6 \%$ & $9,5 \%$ & $18,9 \%$ & $100 \%$ & \\
\hline
\end{tabular}

Fuente: elaboración propia sobre base de datos de OPDS.

\subsection{Municipios}

Si bien las Resoluciones fueron dictadas por un organismo provincial, son los municipios los que tienen fundamental injerencia en la gestión de los residuos de sus respectivos distritos. Algunos estudios muestran que las formas de articulación de los municipios con las jurisdicciones superiores (provincia,

12 Los diez casos registrados abarcan a cinco cooperativas y dos fundaciones, de los cuales solamente una cooperativa cuenta con vehículos propios. Esto hace suponer que el transportista de residuos reciclables consignado en los planes de gestión de los grandes generadores es en realidad el destino sustentable, mientras que el transportista real es una empresa privada, probablemente no habilitada como transportista para grandes generadores industriales. 
nación) varían según el área de política y la jurisdicción, y que si bien existe una creciente articulación entre gobierno municipal y gobierno nacional en el área ambiental (donde se suele incluir la gestión de los residuos), cuando esa articulación no existe o es escasa, disminuye la capacidad de implementación de una política pública por parte del gobierno municipal (Alonso, et. al., 2015). En este sentido, pocos municipios acompañaron a las Resoluciones sancionando instrumentos normativos (ordenanzas) que también obligan a los grandes generadores a separar sus residuos y reconocen a las cooperativas como tratadores de los mismos. Se destacan en este sentido los casos de los Municipios de Quilmes (Ordenanza núm. 12554/16), Lomas de Zamora (Ordenanza núm. 16161/17) y Almirante Brown (Ordenanza núm. 10742/16). No obstante, la mayoría de los municipios han sido indiferentes a las mismas y prácticamente no existe coordinación entre los municipios y el OPDS en este tema. Esta situación también fue registrada en el taller:

TABLA 4. REPORTE DE MESAS DE TRABAJO EN EL $1 .^{\circ}$ ENCUENTRO ENTRE COOPERATIVAS DE RECUPERADORES URBANOS Y UNIVERSIDADES

Taller de evaluación de la implementación de las Resoluciones del OPDS. UNAJ 3-08-2015. INFORME TÉCNICO núm. 1

\section{Mesa 1: información y acceso como destino sustentable}

«Se destacó la falta de articulación entre OPDS y Municipios para exigir a los grandes generadores radicados en sus jurisdicciones la adecuación y el cumplimiento de las Resoluciones. Esa articulación se consideró necesaria. Además, se instó a que los municipios deben informar a los grandes generadores de todos los destinos sustentables habilitados, y no sugerir a los grandes generadores sólo algunos con los que eventualmente algún agente municipal pueda tener vinculaciones».

Fuente: elaboración propia en base a los diálogos del taller.

\subsection{Certificados}

Como no todas las cooperativas lograron inscribirse en el Registro de Tecnologías para actuar como destinos sustentables, se puso en práctica entre ellas un sistema informal de préstamos de los certificados de tratamiento. Esto es, una cooperativa habilitada realiza el certificado electrónico para que otra cooperativa (no habilitada) lo entregue a su cliente. En otro de los encuentros organizados en el marco de los proyectos antes mencionados ${ }^{13}$, varios referentes de cooperativas solicitaron a sus colegas que se sumaran a esta práctica y compartieran la habilitación y los certificados. Si bien la iniciativa fue originalmente avalada por el OPDS para que todas las cooperativas pudieran usufructuar los beneficios de la normativa, de acuerdo a las entrevistas mantenidas con técnicos de OPDS, ello dejó de ser aceptado con el cambio de gestión de diciembre de 2015.

\section{SOBRE LA RELACIÓN ENTRE GRANDES GENERADORES Y DESTINOS SUSTENTABLES SEGÚN LOS PLANES DE GESTIÓN}

A continuación se analizan la relación que han venido estableciendo los grandes generadores y los destinos sustentables, a partir de los datos que surgen de los planes de gestión presentados al OPDS. Además se hará referencia a algunos casos en los que grandes generadores entregan sus residuos reciclables a cooperativas de recuperadores urbanos para su tratamiento, ya sea en el marco de las Resoluciones analizadas como en función de acuerdos establecidos por fuera de las mismas (dado que se refieren a grandes generadores que aún no se encuentran alcanzados por las Resoluciones).

De acuerdo a la información que suministra OPDS en su sitio web, hasta diciembre de 2017 se habían otorgado 38 habilitaciones a destinos sustentables, de los cuales 29 eran cooperativas, siete asociaciones civiles, una fundación y una empresa privada. Ahora bien, al analizar la base de datos Excel suministrada

13 “Jornadas para el Debate Programático 2016. (Re)Pensar la gestión de residuos reciclables en la Provincia de Buenos Aires. Reciclaje Inclusivo + Economía Circular”, 4 de julio de 2016, Universidad Nacional de Quilmes, Roque Sáenz Peña 352, Bernal. 
GAPP. Nueva Época - N. 21, Mayo-Octubre 2019 - ISSN: 1989-8991 - DOI: 10.24965/gapp.v0i21.10559 - [Págs. 61-79]

Fortalezas, debilidades y oportunidades de la política de gestión diferenciada de residuos para grandes generadores del área...

Faustina Sarandón / Pablo Javier Schamber

por el propio OPDS, sólo 13 de esas 29 cooperativas aparecen como destino sustentable en los planes de gestión de los grandes generadores, mientras surgen de allí 17 empresas privadas como destino sustentable (aunque sólo una de ellas estaría habitada como tal). El contraste entre las dos fuentes del OPDS (sitio web y registro en base de datos Excel de los planes de gestión) respecto de los tipos de destinos sustentables se aprecia en la Tabla 5.

TABLA 5 TIPOS DE DESTINOS SUSTENTABLE SEGÚN FUENTE CONSULTADA

\begin{tabular}{cccccccc}
\hline \multicolumn{10}{c}{ Tipo de Destinos sustentables } \\
\hline \multicolumn{10}{c}{ según sitio web de OPDS } \\
Coop. & $\begin{array}{c}\text { Asoc. } \\
\text { civiles }\end{array}$ & Fund. & $\begin{array}{c}\text { Empresas } \\
\text { privadas }\end{array}$ & Coop. & $\begin{array}{c}\text { Asoc. } \\
\text { civiles }\end{array}$ & Fund. & $\begin{array}{c}\text { Empresas } \\
\text { privadas }\end{array}$ \\
\hline 29 & 7 & 1 & 1 & 13 & 2 & 2 & 17 \\
\hline
\end{tabular}

Fuente: elaboración propia sobre base de datos y sitio web OPDS.

Los Planes de Gestión presentados a OPDS por los grandes generadores identifican el destino sustentable que trataría su fracción de residuos reciclable. La Tabla 6 permite apreciar los tipos de figura jurídica de los destinos sustentables identificados en los Planes de Gestión de acuerdo al tipo de Resolución en la que el gran generador se encuentra involucrado.

TABLA 6: TIPOS DE FIGURA JURÍDICA DE LOS DESTINOS SUSTENTABLES IDENTIFICADOS EN LOS PLANES DE GESTIÓN DE LOS GRANDES GENERADORES PRESENTADOS A OPDS, SEGÚN RESOLUCIÓN A LA QUE PERTENECEN

\begin{tabular}{|c|c|c|c|c|}
\hline \multirow{2}{*}{ Tipo de figura jurídica del destino sustentable } & \multicolumn{3}{|c|}{ Resoluciones } & \multirow{2}{*}{ Total } \\
\hline & 137 & 138 & 139 & \\
\hline Cooperativa & 52 & 10 & 8 & 70 \\
\hline Varias Cooperativas & 1 & 1 & 1 & 3 \\
\hline Coop. + Asoc. Civil & 4 & 0 & 0 & 4 \\
\hline Coop. + Privado & 1 & 1 & 0 & 2 \\
\hline Asoc. Civil & 34 & 1 & 5 & 40 \\
\hline Fundación & 0 & 0 & 1 & 1 \\
\hline Ceamse & 89 & 8 & 13 & 110 \\
\hline Ceamse + Asoc. Civil & 22 & 0 & 0 & 22 \\
\hline Ceamse + Asoc. Civil + Coop. & 23 & 0 & 0 & 23 \\
\hline Municipal & 4 & 1 & 1 & 6 \\
\hline Privado & 17 & 13 & 27 & 57 \\
\hline Privado + Coop. & 0 & 0 & 1 & 1 \\
\hline Privado + Fundación & 0 & 0 & 4 & 4 \\
\hline Casos que no son destinos sustentables & 7 & 0 & 5 & 12 \\
\hline No identifica a nadie & 39 & 11 & 27 & 77 \\
\hline Total & 293 & 46 & 93 & 432 \\
\hline
\end{tabular}

Fuente: elaboración propia sobre base de datos de OPDS. 
Si bien allí puede advertirse que CEAMSE lidera las preferencias, en realidad la recepción y el tratamiento se haría en algunas de las nueve Plantas Sociales situadas en el Reciparque de CEAMSE, que son gestionadas por distintas cooperativas y asociaciones civiles, aunque sólo una de ellas se encuentra habilitada por OPDS (Álvarez, 2011) ${ }^{14}$. En orden descendente sí se ubican cooperativas, luego privados y finalmente asociaciones civiles. Hay casos que presentan más de un destino sustentable, incluyendo combinaciones entre distintas figuras jurídicas. También puede notarse que las cooperativas y asociaciones civiles predominan entre los grandes generadores involucrados en las Resoluciones 137 y 138, mientras que los privados se afianzan en relación a la Resolución 139. En los planes de gestión que identificaron a cooperativas como destino sustentable se aprecia una importante concentración; de hecho, un solo caso representa el $40 \%$, mientras que el siguiente representa casi el $26 \%$. Es decir que dos cooperativas aparecen como destinos sustentables exclusivos de casi el $66 \%$ de los grandes generadores que optaron por dicha figura jurídica.

\section{TABLA 7: DISTRIBUCIÓN DE DESTINOS SUSTENTABLES QUE SON COOPERATIVAS EN LOS PLANES DE GESTIÓN DE LOS GRANDES GENERADORES SEGÚN LA RESOLUCIÓN A LA QUE PERTENECEN}

\begin{tabular}{lcccc}
\hline \multirow{2}{*}{ Cooperativas } & \multicolumn{3}{c}{ Resoluciones } & Total \\
\cline { 2 - 5 } & 137 & 138 & 139 & 28 \\
\hline Creando Conciencia & 26 & 1 & 1 & 18 \\
\hline Reciclado del Norte & 14 & 2 & 2 & 2 \\
\hline Villa Itatí & 1 & 1 & 0 & 3 \\
\hline Dignidad Laboral & 0 & 1 & 2 & 2 \\
\hline Nuevamente & 2 & 0 & 0 & 5 \\
\hline Integrar & 5 & 0 & 0 & 6 \\
\hline Cartoneros Platenses & 3 & 2 & 1 & 1 \\
\hline Jóvenes en progreso & 0 & 0 & 1 & 1 \\
\hline Andresito & 1 & 0 & 0 & 1 \\
\hline Álamo & 0 & 1 & 0 & 1 \\
\hline Nuevo Rumbo & 0 & 1 & 0 & $\mathbf{7 0}$ \\
\hline Del Sur & 0 & 1 & 0 & 1 \\
\hline Reciklándonos 2 & 0 & 0 & $\mathbf{8}$ & 1 \\
\hline Total & $\mathbf{5 2}$ & $\mathbf{1 0}$ & $0 P 0$ & 1 \\
\hline
\end{tabular}

Fuente: elaboración propia sobre base de datos de OPDS.

\subsection{Algunos casos}

Varios de los casos de grandes generadores que entregan sus residuos reciclables a cooperativas se enmarcan en las Resoluciones analizadas, mientras que otros son acuerdos establecidos por fuera de las mismas, como sucede con las Universidades Nacionales. Su consideración pretende ilustrar las modalidades que pueden tener estas relaciones, y en base a su análisis, sugerir orientaciones de modificaciones deseables.

${ }^{14}$ En realidad, CEAMSE no es un destino sustentable y de hecho no figura como tal en el listado del sitio web de OPDS, pero hasta el cambio de gestión de diciembre de 2015, pudo emitir certificaciones por la recepción y tratamiento que hacían las «Plantas Sociales» ubicadas en el RECIPARQUE del Complejo Ambiental Norte III. Desde entonces, son las respectivas organizaciones que gestionan las Plantas Sociales las que deben hacerlo. 


\subsubsection{Asociación Vecinal Nordelta ${ }^{15}$ y Coop. Creando Conciencia (Res. 137)}

La Asociación Vecinal Nordelta y la cooperativa Creando Conciencia trabajan en forma conjunta desde 2010, es decir, con anterioridad al establecimiento de las Resoluciones. Esta cooperativa surgió en el año 2005 promovida por un grupo de vecinos, «con gran preocupación por la disposición final de los residuos sólidos urbanos, por la problemática de los recuperadores urbanos (cartoneros) y por la posibilidad de generar alternativas que enfrenten estas problemática con responsabilidad social y sustentabilidad» según detallan en su página web (http://www.creandoconciencia.com.ar/). Esta organización brinda empleo a 44 socios (para poder trabajar en la cooperativa primero hay que asociarse a ella), 25 de los cuales están en la planta de separación que tienen en la localidad de Benavidez, mientras que los restantes 19 se dedican a la recolección de los residuos (choferes, corredores, supervisores). En octubre de 2017 las escalas de ingresos iban desde los 8.000 \$ para los que recién ingresaban, hasta cinco veces esa cifra en el caso de los puestos directivos y jerárquicos ${ }^{16}$. Algunos socios perciben ingresos adicionales del sistema de seguridad social gestionados por la Cooperativa, mientras que otros participan de un plus por las ventas de reciclables; y es la cooperativa la encargada del pago del monotributo social y de otras cargas sociales. La cooperativa cuenta con cinco camiones del tipo caja seca (dos grandes y tres medianos), más un camión cola de pato y otro de carga lateral. Además en el galpón tienen cinta transportadora, enfardadora y montacargas.

Creando Conciencia brinda a Nordelta distintos tipos de servicios: retiro de residuos en general con frecuencia de seis veces a la semana, retiro de materiales reciclables tres veces a la semana, retiro de ecopuntos una vez a la semana. A su vez tiene diferentes clientes (distintos a la Asociación) dentro del complejo Nordelta, como la estación de combustibles Petrobras y algunos comercios. En función de lo expresado por su presidente en oportunidad de una entrevista para este trabajo, los ingresos de la cooperativa se conforman en un $80 \%$ por el cobro de los servicios a todos los clientes y en un $20 \%$ por la venta del material reciclable que separan de estos retiros (en promedio 90 toneladas mensuales de distintos materiales). Además de Nordelta, Creando Conciencia tiene otros 15 clientes (otros barrios cerrados y/o countries) y acaba de ganar una licitación como proveedor de servicios para Natura Cosméticos.

\subsubsection{Clorox SA., Reciclando Sueños, Consejo Nacional de Investigaciones Científico Tecnológicas (CONICET) (Res. 139/13)}

La Cooperativa Reciclando Sueños se inició en el año 2003 como grupo de trabajo y en el 2008 se formalizó como Cooperativa de provisión de servicios. Realiza la recolección y tratamiento de los residuos reciclables de algunas zonas del municipio de La Matanza y ofrece servicios a grandes generadores. Poseen un galpón de aproximadamente $250 \mathrm{~m}^{2}$ de superficie, donde tratan distintos materiales. La Cooperativa trabaja en conjunto con un equipo de investigadores del CONICET desde hace ya muchos años (una síntesis de la relación se puede apreciar en http://www.conicet.gov.ar/reciclandosuenos-valorizacion-de-residuos-e-innovacion-tecnologica-desde-la-base/). Investigadores y becarios asesoran y acompañan a la Cooperativa para su inscripción como proveedor de Clorox Argentina S. A., una empresa internacional de productos de limpieza para el hogar. A su vez equipos integrados por investigadores y miembros de la cooperativa capacitan a los trabajadores de la empresa sobre la gestión de residuos basada en reciclaje inclusivo. El servicio de retiro del material reciclable y la capacitación es pagado por la empresa como lo hace con cualquier otro proveedor contratado. En el sitio web de la empresa puede leerse:

Desde hace tres años hacemos foco en una Plataforma de Reciclaje Inclusivo, promoviendo una sinergia entre distintos actores sociales: el CONICET, desarrolla contenidos y brinda capacitaciones; la Cooperativa Reciclando Sueños, gestiona los residuos de la planta, capacita a empleados y a la comunidad; el OPDS (Autoridad ambiental provincial) y el CARE (Autoridad ambiental municipal)acompañan e impulsan el proyecto y los empleados de Clorox que forman

15 Nordelta en el Municipio de Tigre es un gran emprendimiento inmobiliario de $16 \mathrm{~km}^{2}$ con 23 Barrios privados en los que habitan más de 30.000 personas (https://www.nordelta.com/).

${ }^{16}$ Sirva como referencia que de acuerdo a datos del Instituto Nacional de Estadísticas y Censos de Argentina, en septiembre de 2017 una familia tipo (dos adultos y dos niños de entre 6 y 8 años) necesitó ingresos por 15.451,58 pesos para poder adquirir la cantidad de bienes y servicios que componen la Canasta Básica Total y no caer por debajo de la línea de pobreza. 
GAPP. Nueva Época - N. 21, Mayo-Octubre 2019 - ISSN: 1989-8991 - DOI: 10.24965/gapp.v0i21.10559 - [Págs. 61-79]

Fortalezas, debilidades y oportunidades de la política de gestión diferenciada de residuos para grandes generadores del área..

Faustina Sarandón / Pablo Javier Schamber

parte del voluntariado a los colegios de la comunidad (http://www.clorox.com.ar/sustentabilidadfuturo-limpio.php).

\subsubsection{Grupo Newsan y Cooperativa Bella Flor}

La Cooperativa Bella Flor es una de las pocas habilitadas como destino sustentable dentro del conjunto de organizaciones que gestionan las Plantas Sociales que se encuentra en el Reciparque del Complejo Ambiental de CEAMSE Norte III. El Grupo Newsan reúne varias marcas que fabrican electrodomésticos (televisores, aires acondicionados, microondas, audios). Desde mediados del año 2016 implementa en su principal sede administrativa de la Ciudad Autónoma de Buenos Aires (CABA) un programa de separación de residuos denominado "Oficina Verde" que consiste en la separación de residuos en cinco fracciones distintas: papel, plástico, aluminio, orgánicos y basura no recuperable. Bella Flor realiza el retiro de los materiales, los transporta y los trata en su Planta Social del Reciparque, pero no cobra por el servicio de tratamiento, como de hecho tampoco lo hacen otras organizaciones situadas en CEAMSE con sus respectivos proveedores, aunque en este caso sí cobran por el servicio de recolección. Para poder acceder a esta relación, la Cooperativa tuvo que cumplir con ciertos requisitos para inscribirse como proveedores de esta empresa. En este sentido, el encargado del área de Sustentabilidad de la misma expresó:

Trabajamos en un proceso de desarrollo super interesante que duró 3 o 4 meses y en donde tuvimos que ajustar algunas cuestiones que nosotros necesitábamos en nuestros procesos internos, que van por ejemplo desde cómo paga una compañía, que por ahí dista mucho de lo que una cooperativa necesita. Hay procesos más largos o complejos que en el caso de trabajar con una cooperativa necesitamos flexibilizar. Esto fue un aprendizaje interno muy interesante y enriquecedor. Y por el otro lado, ayudar a la cooperativa que pueda desarrollar algunas cuestiones que le permitieran habilitarse como proveedora de Newsan. Por ejemplo, saber que todos los meses tienen que ingresar a una página web y cargar el alta de ART (seguro de riesgo de trabajo) de sus empleados, que constantemente van a estar siendo sometidos a auditorías para comprobar si efectivamente sus empleados están en blanco, que si su horario de retiro es entre las 6:01 y las 6:30 PM y llegan 6:35 PM, el guardia de seguridad no va a apretar el botón para abrirles porque hay un protocolo de seguridad atado a eso. Ayudarlos en la definición de la logística para que el retiro de materiales pueda sumar a otras empresas de la zona y se puedan reducir las emisiones de $\mathrm{CO} 2$ asociadas. En fin, un trabajo bien interesante que desarrollamos en conjunto con áreas de gobierno (que se encarga de la articulación público-privada), compras, complaince (conformidad) de la compañía. Todo un trabajito que fuimos desarrollando con ellos para poder tenerlos como proveedores (Germán, responsable de Sustentabilidad Grupo Newsan).

\subsubsection{Carrefour, Mc Donald's (Res. núm. 138/13) y varios destinos sustentables}

Los 14 hipermercados que Carrefour tiene en el AMBA obtuvieron la aprobación del OPDS de su único Planes de Gestión en el año 2015. La empresa no presentó esta situación como el cumplimiento de una normativa, sino como un «convenio» y como un «acuerdo» entre partes, tal como en su sitio web puede leerse:

«Estamos muy orgullosos de ser el primer retail en suscribir a este acuerdo que precisa cuales son nuestros procedimientos a la hora de gestionar los residuos que generamos. Este plan lo venimos implementando desde hace más de un año y esta presentación oficial de la mano de OPDS nos da el empuje necesario para seguir implementando acciones que nos posicione como una empresa ambientalmente responsable, aseguró Javier Potasman, Director del Centro de Compras Indirectas de Carrefour Argentina» (https://www.carrefour. com.ar/content/OPDS-aprobo-el-plan-de-gestion-de-residuos-propuesto-por-carrefour/, visto el 29-05-2018)

Las distintas sedes de este hipermercado tienen diferentes destinos sustentables que recolectan y tratan los residuos. Varios informantes consultados relataron que en los acuerdos entre la empresa y las cooperativas tuvo que mediar el OPDS, dado que inicialmente la empresa se negaba a entregar ciertos 
materiales reciclables porque los vendía, a pesar de no estar habilitados para realizar un comercio de este tipo. Como ninguna cooperativa garantizaba capacidad operativa para procesar los residuos de todas las sedes, decidieron compartirlas entre varias. Esta complementariedad entre las cooperativas genera la posibilidad de cubrir territorios extensos y, por sobre todo, que puedan trabajar cooperativas aunque no se encuentren registradas como destinos sustentables, ya que el certificado es emitido sólo por una. La misma complementariedad sucede en el caso de las sucursales de Mc Donald's, donde una cooperativa es la que formalmente figura como destinos sustentables, aunque son varias las que realizan la recolección y el tratamiento de sus residuos. Tal como se indicó más arriba, este tipo de complementariedad entre varias cooperativas no es avalada por el OPDS, aunque tampoco interviene restringiéndola.

\subsubsection{Universidades Nacionales del Conurbano y cooperativas}

Las Universidades Nacionales quedaron excluidas de las Resoluciones, no obstante lo cual en los últimos años varias han comenzado a llevar a cabo sistemas de separación interna de residuos, y han establecido contacto con cooperativas de recuperadores para el retiro (un primer registro de estas experiencias puede encontrarse en AA.VV, 2016: Jornada Universidades y Desarrollo Sustentable). Un indicador de la potencialidad que tiene este tipo de experiencias, es la recientemente creación de la Red de Universidades Argentinas para la Gestión Ambiental y la Inclusión Social (UANGAIS) y en la que se han definido representantes por región (CIN, 2018). A continuación se describen brevemente tres casos y luego se presentan sus características principales en un cuadro.

\subsubsection{Universidad Nacional de San Martín (UNSAM) y Coop. Reciklandonos II $^{17}$}

En la Secretaría de Extensión de esta Universidad se desarrolla el proyecto ECOUNSAM a través del cual se comenzó a clasificar materiales reciclables en el campus universitario, y luego con el apoyo del Rectorado se creó el más amplio programa UNSAM Sustentable (http://www.unsam.edu.ar/sustentable). Desde ese marco institucional se establecieron relaciones con el municipio de San Martín para coordinar el retiro de dicho material y su posterior traslado a una planta de tratamiento correspondiente a la cooperativa Reciklandonos II, que se encuentra habilitada como destino sustentable por el OPDS.

\subsubsection{Universidad Nacional de Quilmes (UNQ) y Coop. Comandante Andresito}

En la UNQ el Programa Institucional Interdisciplinario de Intervención Socio Ambiental (PIIdISA) estableció un convenio con la cooperativa Comandante Andresito (reconocida como destino sustentable por el OPDS) que comenzó a implementarse en el año 2017, mediante el cual se acordó el retiro de la fracción reciclable generada en uno de los edificios del predio de la Universidad en la localidad de Bernal. La iniciativa se sostiene en el marco de un proyecto de extensión universitaria con financiamiento de la Secretaria de Políticas Universitaria del Ministerio de Educación de la Nación.

\subsubsection{Universidad Nacional de Lanús (UNLa) y Coop. Cartón y Justicia (CCyJ)}

La Cooperativa Cartón y Justicia (CCyJ) de Lanús comenzó en octubre de 2017 a retirar restos de embalajes y envases del comedor de la Universidad Nacional de Lanús (UNLa). La cooperativa brinda un servicio diario de recolección selectiva en el centro del municipio de Lanús en función de un acuerdo alcanzado con el propio Municipio, y aprovechando el transporte con el que hacen dicha recolección, también retiran los residuos reciclables de la Universidad. Esta iniciativa forma parte de un proyecto de investigación y transferencia que busca incorporar pautas relativas a la clasificación de los residuos en dicha unidad académica.

A modo de síntesis de ciertos aspectos clave de las experiencias mencionadas, se presenta a continuación la Tabla 8:

17 Agradecemos la información suministrada por la Lic. España Verrastro de la UNSAM. 
GAPP. Nueva Época - N. 21, Mayo-Octubre 2019 - ISSN: 1989-8991 - DOI: 10.24965/gapp.v0i21.10559 - [Págs. 61-79]

Fortalezas, debilidades y oportunidades de la política de gestión diferenciada de residuos para grandes generadores del área..

Faustina Sarandón / Pablo Javier Schamber

TABLA 8. SÍNTESIS DE LAS EXPERIENCIAS ENTRE UNIVERSIDADES Y COOPERATIVAS DE RU

Las experiencias tienen aún muy poco tiempo de desarrollo y antigüedad.

La generación de residuos reciclables es irregular, en el sentido en que las cantidades producidas pueden variar mucho con diferencia de pocos días.

Las unidades académicas deben resolver internamente como acercar los materiales depositados en los espacios de separación inicial a los sitios escogidos para la contenerización y el acopio desde donde serán retirados de la institución.

Raramente el servicio es abonado por las universidades, y suele verse subsidiado el transporte por los Municipios.

No suele haber registros de la evolución del peso y la calidad de lo que se retira, en parte debido a que para el aprovechamiento de la logística el material se mezcla con lo proveniente de otras fuentes.

Fuente: elaboración propia.

\section{REFLEXIONES FINALES}

En la introducción se planteó que la Ley 14273 de grandes generadores que antecedió a las Resoluciones implicaba un beneficio directo hacia CEAMSE y hacia las empresas transportistas, y no guardaba relación con los principios que orientan la valorización de los residuos. Se excluía a los grandes generadores del servicio de recolección municipal para poder cobrarles y responsabilizarlos por los costos del transporte y la disposición de sus residuos, beneficiando a transportistas privados y al CEAMSE. Las Resoluciones, por el contrario, propician en los grandes generadores la separación en origen de los RSU y fomentan el reciclaje, y además abren un escenario de oportunidades para que las cooperativas de recuperadores urbanos participen como oferentes de los servicios. Sin embargo, analizando algunos resultados vinculados a su implementación, se notan nuevamente beneficios a las empresas transportistas (especialmente en lo relacionado a la Resolución 139), y a la CEAMSE (como principal receptor en sus Plantas Sociales de los residuos reciclables).

Las cooperativas de recuperadores urbanos de la provincia de Buenos Aires se encuentran en distintas condiciones en su proceso de formalización y organización, así como presentan situaciones heterogéneas en cuanto a equipamiento e infraestructura. Ello establece diferencias importantes respecto a la posibilidad real de participar de forma más o menos inmediata de las oportunidades que ofrecen las Resoluciones que fueron objeto de análisis. En el caso de los grandes generadores, se desconoce el universo de quienes se encontrarían involucrados. Para aquellos que obtuvieron la aprobación de su respectivo plan de gestión (una mínima porción de los que lo presentaron) la contratación como destino sustentable de cooperativas en lugar de empresas privadas, algo que OPDS recomienda cuando recibe consultas, requiere esfuerzos adicionales para el cumplimiento de los requisitos establecidos a cualquier proveedor de servicios, y no todos los grandes generadores consideran que esa relación repercute positivamente en la valoración social de la empresa. Las cooperativas suelen presentar variados inconvenientes a la hora de cumplir los estándares que reclaman los grandes generadores, ya sea en cuestiones formales de su personal (uniforme, conducta, seguros) como en aspectos que hacen al servicio (cumplimiento de horarios, regularidad, trazabilidad, confección y entrega de certificación). La antigüedad y condiciones en que se encuentran los vehículos (propios o cedidos por Municipios) también puede ser un elemento que incumpla requisitos del gran generador. Como pudo notarse, ni la presentación de planes de gestión por parte de los grandes generadores implica el cumplimiento de las Resoluciones, ni la habilitación como destino sustentable asegura conseguir clientes. Se advierte en muchos grandes generadores resistencia al pago por el servicio que ofrecen los destinos sustentables que son cooperativas, pero también consentimiento de algunas en que dicha situación continúe dándose. Las entregas gratuitas de residuos reciclables previas a las Resoluciones son argumentaciones que de uno y otro lado justifican esos casos. EI OPDS rehúye la demanda de un sector de las cooperativas que plantean exigir el pago por servicios de tratamiento.

Los casos analizados permiten observar la importancia de que exista buena voluntad por parte del gran generador (Clorox y Newsan) o acompañamiento por parte de instancias estatales (CONICET, Universidades, Municipios y el propio OPDS) para que las cooperativas puedan competir como prestadoras de servicios. Sin este acompañamiento para su formalización y la vocación por la profesionalización según 
estándares requeridos por los grandes generadores para cualquier proveedor de servicios, las cooperativas enfrentan muchísimas dificultades para conseguir clientes entre los grandes generadores y para poder cobrar por el servicio de retiro y tratamiento de los residuos.

La posibilidad de brindar servicios a quienes tienen la obligación de contratarlos fue interpretada como una beneficiosa coyuntura que traían las Resoluciones para las cooperativas, aunque ello no evitó manifestaciones de temor frente a la eventualidad de la competencia con empresas privadas dotadas inicialmente de mayores ventajas. Temor fundado no sólo en el hecho de que varias consultoras ambientales y empresas transportistas incluyeran también en su oferta a los grandes generadores el tratamiento de los residuos al inscribirse como destinos sustentables, sino porque al ser más simple la inscripción en el Registro de Tecnologías para cooperativas y asociaciones civiles, muchos prestadores privados eligieran esa figura jurídica para identificarse. Además el OPDS fue incorporando requisitos adicionales para las cooperativas antes de proceder al dictamen respecto de su habilitación (las visitas de inspección técnica in situ), mientras que la obligatoriedad relacionada con la presentación anual de planes de gestión a la que están compelidos los grandes generadores ha quedado soslayada. En efecto, el OPDS centró sus esfuerzos en realizar visitas técnicas a las cooperativas e inspeccionar su propuesta de trabajo como destinos sustentables, mientras que existe un gran número de grandes generadores que jamás presentó planes de gestión, y entre quienes los presentaron, sólo logró aprobación el $5 \%$.

Es cierto que varios referentes de cooperativas han reconocido que el OPDS recomienda a los grandes generadores que se vinculen con ellas en tanto destinos sustentables, pero el análisis realizado sobre la base de datos construida con los planes de gestión presentados demuestra que dichas recomendaciones no fueron tenidas muy en cuenta. Asimismo también se han evidenciado eventos en los que OPDS ha participado divulgando las Resoluciones en instalaciones de grandes generadores acompañando a prestadores de servicio de retiro, transporte y tratamiento provenientes del sector privado.

A cuatro años de la existencia de las Resoluciones, la adhesión por parte de los grandes generadores involucrados fue escasa y en muchos casos no reconocida como el cumplimiento de una normativa estatal sino presentada como una estrategia de sustentabilidad de la propia empresa. Más allá de algunas cartas documento enviadas por OPDS al inicio del período analizado, no hubo casos de sanción a grandes generadores incumplidores. Simultáneamente, pareciera notarse sin embargo un mayor esfuerzo fiscalizador hacia las cooperativas antes y después de otorgarles la habilitación como destinos sustentables. Ello pone en duda el desempeño del OPDS como promotor del reciclado con inclusión social, ya que la complejidad de los actores involucrados, cuyas lógicas difieren mucho entre sí, hace que no sea suficiente la sola sanción de una normativa con espíritu inclusivo, sino que es necesario un acompañamiento más profundo y ejercicio de control de que sean los grandes generadores privados quienes principalmente cumplan con su obligación. $\mathrm{Si}$ bien quienes tienen mayores clientes entre los grandes generadores son cooperativas en comparación con empresas privadas, esto no quiere decir que las Resoluciones hayan sido exitosas para la inclusión social de los recuperadores urbanos asociados a ellas. De hecho, de las 29 cooperativas y siete asociaciones civiles habilitados como destinos sustentables registrados en el OPDS, sólo 13 consiguieron como clientes a grandes generadores.

Con la sanción de las Resoluciones se creó un espacio de diálogo entre las partes involucradas (OPDS, grandes generadores, destinos sustentables) que consistía en reuniones periódicas, pero las mismas se han venido diluyendo y han perdido regularidad. Ese espacio fue mencionado por varios entrevistados como un ámbito indispensable para procurar mejoras en la implementación de las Resoluciones. Los talleres organizados desde proyectos universitarios de investigación y transferencia cuyos informes y registros se emplearon como fuente, tuvieron el mismo reconocimiento. Esperamos que este trabajo sea también un renovado aporte en tal sentido.

\section{REFERENCIAS BIBLIOGRÁFICAS}

AA.VV (2016): Jornada Universidades y Desarrollo Sustentable. Maestría y Especialización en Ambiente y Desarrollo Sustentable. La letra del Encuentro, Intercambios. Secretaría de Posgrado Universidad Nacional de Quilmes. 1. ${ }^{a}$ edición, mayo de 2016. Edición electrónica en PDF, 210 págs., 13 mb. Disponible para descarga: http://posgrado. blog.unq.edu.ar/y https://issuu.com/posgradounq/docs/ambiente_63f1ebc3e21ce5.

AA.VV (2016): Informe técnico núm. 1, Proyecto UNAJ SPU 4663/14 núm. 001-107 (mimeo).

AA.VV (2016): Jornada de debate con cooperativas de cartoneros y recuperadores. Maestria y Especialización en Ambiente y Desarrollo Sustentable. La letra del Encuentro, Intercambios. Secretaría de Posgrado Universidad 
GAPP. Nueva Época - N. ${ }^{2}$ 21, Mayo-Octubre 2019 - ISSN: 1989-8991 - DOI: 10.24965/gapp.v0i21.10559 - [Págs. 61-79]

Fortalezas, debilidades y oportunidades de la política de gestión diferenciada de residuos para grandes generadores del área..

Faustina Sarandón / Pablo Javier Schamber

Nacional de Quilmes. 1. ${ }^{a}$ edición, Abril. Edición electrónica en PDF, 90 págs., 1,81 mb. Disponible en web: http:// posgrado.blog.unq.edu.ar/y https://issuu.com/posgradounq/docs/ambiente.

AGUILAR VILLANUEVA, L. (1993): “Estudio introductorio”, en AGUILAR VILLANUEVA, L. (ed.): La implementación de las políticas. México D. F.: Miguel Ángel Porrúa.

AGUILAR VILLANUEVA, L. (1996): "Estudio introductorio", en AGUILAR VILLANUEVA, L. (ed.): Problemas públicos y agenda de gobierno. México D. F.: Miguel Ángel Porrúa.

ALONSO, G., GUTIÉRREZ, R. y MERLINSKY, G. (2016): "Federalismo y políticas municipales en la Región Metropolitana de Buenos Aires. Los desafíos de articulación interjurisdiccional en dos casos de estudio (Avellaneda y San Martín)", en Gestión y Política Pública, vol. XXV, núm. 2, págs. 483-523. Disponible en web: http://www.redalyc.org/jatsRepo/133/13346618004/index.html.

ÁlVAREZ, R. N. (2011): La basura es lo más rico que hay. Relaciones políticas en el terreno de la basura. El caso de Ios quemeros y los emprendimientos sociales en el relleno Norte III del CEAMSE. Buenos Aires: Editorial Dunken.

ANGÉLICO, H. y MALDOVAN, J. (2008): "El reciclaje de residuos sólidos urbanos: las cooperativas como un actor diferenciado en el circuito productivo", en Revista de la Cooperación Internacional, vol. 41, núm. 2, págs. 79-107.

BUSSO, M. (2004): Los trabajadores informales y sus formas de organización colectiva. Un estudio en ferias de la Ciudad de La Plata [Tesis de Maestría]. Buenos Aires (inédito).

CONSEJO INTERUNIVERSITARIO NACIONAL (2018): "Gestión de residuos", en Revista Actualidad Universitaria, Año XVII, núm. 76 "Te quiero verde", noviembre-diciembre, págs. 4-11.

DIMARCO, S. (2010): Entre el trabajo y la basura: socio-historia de la clasificación de residuos en la Ciudad de Buenos Aires (1870-2005) [Tesis del Doctorado en Ciencias Sociales], Universidad de Buenos Aires (inédito).

GORBAN, D. (2005): Formas de organización y espacio. Reflexiones alrededor del caso de los trabajadores cartoneros de José León Suárez [Tesis de Maestría]. Universidad de Buenos Aires, Facultad de Ciencias Sociales (inédita).

MALDOVAN BONELLI, J. (2017): Del trabajo autónomo a la autonomía de las organizaciones. La construcción de asociatividad en las cooperativas de recuperadores urbanos de la Ciudad Autónoma de Buenos Aires (20072012). Buenos Aires: Editorial Teseo. Disponible en web: https://www.editorialteseo.com/archivos/15241/deltrabajo-autonomo-a-la-autonomia-de-las-organizaciones/.

MOLINA, N. (2017): Los intermediarios de materiales reciclables. Dimensiones de su rol en el subsistema de reciclaje de Quilmes [Tesis de Maestría en Ambiente y Desarrollo Sustentable]. Universidad Nacional de Quilmes (inédito).

OSZLAK, O. y O'DONNELL, G. (1981): "Estado y políticas estatales en América Latina: hacia una estrategia de investigación", en REDES, núm. 4, septiembre de 1995, págs. 98-128.

PAIVA, V. (2008): Cartoneros y cooperativas de recuperadores. Una mirada sobre la recolección informal. Buenos Aires: Prometeo.

PERELMAN, M. (2010): El cirujeo en la Ciudad de Buenos Aires. Etnografía de la supervivencia [Tesis doctoral].UBA, Facultad de Filosofía y Letras, (inédito).

REGONINI, G. (1990-1991): "El estudio de las políticas públicas", en Revista de Documentación Administrativa (19582005), núms. 224-225, págs. 59-88. Disponible en web: https://revistasonline.inap.es/index.php?journal=DA\&page $=$ article\&op=view\&path\%5B\%5D=5206\&path\%5B\%5D=5260. DOI: 10.24965/da.v0i224-225.5206.

SARANDÓN, F. (2016): La construcción de la relación entre las Cooperativas de Recuperadores Urbanos y el Estado provincial en la implementación de la política de Gestión diferenciada de Residuos Sólidos Urbanos de grandes generadores (2013-2014) [Tesina de grado para la obtención de la Licenciatura en Sociología]. Universidad Nacional de La Plata (inédito).

SCHAMBER, P. y SARANDÓN, F. (2018): GUIA 1: ¿Cómo ser un destino sustentable reconocido por el Organismo Provincial para el Desarrollo Sostenible (OPDS) de la Provincia de Buenos Aires? Disponible en web: http:// programasocioambiental.blog.unq.edu.ar/wp-content/uploaDestinos Sustentables/sites/4/2018/04/Gui\%CC\%81a01-v.2.pdf.

SCHAMBER, P. y SUÁREZ, F. (comp.) (2007): Recicloscopio I. Miradas sobre recolectores urbanos de residuos en América Latina. Buenos Aires: Editorial de la UNLA/UNGS/Promoteo.

SCHAMBER, P. y SUÁREZ, F. (comp.) (2011): Recicloscopio III. Miradas sobre recolectores urbanos, formas organizativas y circuitos de valorización de residuos en América Latina. Buenos Aires: Editorial CICCUS/ UNLA/UNGS.

SCHAMBER, P. J. y BORDAGARAY, M. E. (2017): "Notas acerca de la experiencia del centro de acopio de residuos reciclables (AMBA 1999-2006)", en Revista de Ciencias Sociales, segunda época, año 8, núm. 31, Otoño 2017, publicación semestral, págs. 157-177. Disponible en web: http://www.unq.edu.ar/catalogo/408-revista-de-cienciassociales-n-31.php.

SCHAMBER, P. J. (2008): De los desechos a las mercancías. Etnografía de los cartoneros. Buenos Aires: SB.

SHAMMAH, C. (2009): El circuito informal de los residuos. Los basurales a cielo abierto. Buenos Aires: Espacio.

SORROCHE, S. (2017): "Experiencias replicables. Análisis de las vinculaciones entre cooperativas de cartoneros, agencias estatales y ONG en el Gran Buenos Aires", en Revista de Estudios Sociales, núm. 61. Disponible en web https://revistas.uniandes.edu.co/doi/abs/10.7440/res61.2017.05. DOI: 10.7440/res61.2017.05.

SORROCHE, S. (2016): Gubernamentalidad global y vernaculización en la gestión de residuos. Análisis etnográfico desde la experiencia de cooperativas de cartoneros en el Gran Buenos Aires [Tesis Doc.]. UBA, Fac. Filosofía y Letras, (inédito). 
SUÁREZ, F. y SCHAMBER, P. (comp.) (2011): Recicloscopio II. Miradas sobre recolectores urbanos, politicas públicas y subjetividades en Amércia Latina. Buenos Aires: CiCCUS/UNLA/UNGS.

SUÁREZ, F. y SCHAMBER, P. (comp.) (2015): Recicloscopio IV. Miradas sobre dinámicas de gestión de residuos y organización de recuperadores. Buenos Aires: Editorial UNLA/UNGS.

SUÁREZ, F. M. (1998): Que las recojan y las tiren afuera. Historia de la gestión de residuos sólidos (las basuras) en Buenos Aires. Documento de Trabajo núm. 8. Los Polvorines: UNGS.

SUÁREZ, F. M. (2003): Actores sociales de la gestión de los residuos sólidos de los municipios de Malvinas Argentinas y José C. Paz [Tesis de maestría en Políticas Ambientales y Territoriales], Universidad de Buenos Aires, Facultad de Filosofía y Letras (inédito).

SUÁREZ, F. M. (2014): Las tramas del cartón. Trabajo y familia en los sectores populares del Gran Buenos Aires. Buenos Aires: Editorial Gorla. Colección Etnografía de los sectores populares.

SUÁREZ, F. M. (2016): La Reina del Plata. Buenos Aires: sociedad y residuos. Los Polvorines: Ediciones UNGS.

SUBIRATS, J. (1994): Análisis de políticas públicas y eficacia de la administración. Madrid: Ministerio para las Administraciones Públicas.

TAMAYO SÁEZ, M. (1997): “El análisis de las políticas públicas”, en BAÑóN, R. y CARRILLO, E.: La nueva Administración Pública. Madrid: Alianza Universidad.

VILLANOVA, N. (2015): Cirujas, cartoneros y empresarios. La población sobrante como base de la industria papelera (Buenos Aires, 1989-2012). Buenos Aires: CEICS-Ediciones ryr.

\section{NORMATIVA DE REFERENCIA}

Ley 25916/04 de Gestión de residuos domiciliarios.

Ley 11459/93 de residuos industriales de la Provincia de Buenos Aires.

Ley 11723/95 Integral del Medio Ambiente y los Recursos Naturales de la Provincia de Buenos Aires.

Ley núm. 13592/06 "Gestión de Residuos Sólidos Urbanos" de la Provincia de Buenos Aires.

Ley núm. 14273/11 de grandes generadores de residuos de la Provincia de Buenos Aires.

Resolución núm. 367/10 "Registro de Tecnologías" del Organismo Provincial para el Desarrollo Sostenible de la Provincia de Buenos Aires.

Resolución núm. 137/13 "Plan de Gestión de Residuos Sólidos Urbanos para Clubes de Campo y Barrios Cerrados" del Organismo Provincial para el Desarrollo Sostenible de la Provincia de Buenos Aires.

Resolución núm. 138/13 de grandes generadores de residuos del Organismo Provincial para el Desarrollo Sostenible de la Provincia de Buenos Aires.

Resolución núm. 138/13 sobre Industrias del Organismo Provincial para el Desarrollo Sostenible de la Provincia de Buenos Aires.

Resolución núm. 20/14 "Modifica el Artículo 6. de la Resolución núm. 367/10" del Organismo Provincial para el Desarrollo Sostenible de la Provincia de Buenos Aires.

Ordenanza núm. 12554/16 del municipio de Quilmes. 